\title{
A Study of Characteristics of Aluminum Bronze Coatings Applied to Steel Using Additive Technologies
}

\author{
Marina Samodurova ${ }^{1}$, Nataliya Shaburova ${ }^{2, * \mathbb{D}}$, Olga Samoilova ${ }^{2}$, Liudmila Radionova ${ }^{1}($, \\ Ramil' Zakirov $^{3}$, Kirill Pashkeev ${ }^{4}$, Vyacheslav Myasoedov ${ }^{4}$, Ivan Erdakov ${ }^{5}$ (D) and \\ Evgeny Trofimov ${ }^{2}$ \\ 1 Department of Metal Forming, South Ural State University, Lenin prospect 76, Chelyabinsk 454080, Russia; \\ samodurovamn@susu.ru (M.S.); radionovalv@susu.ru (L.R.) \\ 2 Department of Materials Science, Physical and Chemical Properties of Materials, South Ural State University, \\ Lenin prospect 76, Chelyabinsk 454080, Russia; samoylova_o@mail.ru (O.S.); tea7510@gmail.com (E.T.) \\ 3 Scientific and Educational Center "Engineering", South Ural State University, Lenin prospect 76, \\ Chelyabinsk 454080, Russia; zakirovra@susu.ru \\ 4 Resource Center for Special Metallurgy, South Ural State University, Lenin prospect 76, Chelyabinsk 454080, \\ Russia; pashkeevki@susu.ru (K.P.); vmyasoedov74@mail.ru (V.M.) \\ 5 Foundry Department, South Ural State University, Lenin prospect 76, Chelyabinsk 454080, Russia; \\ erdakovin@susu.ru \\ * Correspondence: shaburovana@susu.ru; Tel.: +7-351-265-6205
}

Received: 26 December 2019; Accepted: 16 January 2020; Published: 18 January 2020

check for updates

\begin{abstract}
The influence of laser power on the microstructural, strength, and tribological characteristics of aluminum bronze coatings applied to steel by laser cladding was studied. It was found that with an increase in laser power, the morphology of the coating surface becomes more uniform without extreme height differences. This study revealed that the coating microstructure corresponds to that of a composite material and consists of a bronze matrix and iron dendrites of different sizes (depending on the laser power). Such a microstructure affects the microhardness indices, which have a scatter of values over the coating thickness. There is a diffusion zone at the steel-bronze interface, which promotes adhesion of the matrix and coating materials. According to the results of tribological tests, the dry friction coefficient for the studied samples is in the range of 0.389-0.574.
\end{abstract}

Keywords: protective coating; aluminum bronze; additive technologies; microstructure; microhardness; tribological characteristics

\section{Introduction}

Copper-alloy details in friction pairs, as well as copper-based coatings applied to steel details of friction units, are widely used in automotive and mechanical engineering due to their tribological properties [1-6].

Along with electric-arc [7] and plasma spraying [8], the method of applying bronze coatings using additive technologies is considered one of the most promising nowadays. However, there are few papers studying additive application technologies and characteristics of the resulting coating [9-12]. Thus, Schmidt et al. [9] described the process of applying aluminum bronze on stainless steel tools using the direct laser deposition (DLD) method. The best results were obtained with a laser power of $3000 \mathrm{~W}$, a distance of $15 \mathrm{~mm}$ from the nozzle to the steel surface, and a small laser beam diameter. The study of mechanical characteristics in [9] showed that the microhardness of a bronze coating obtained using additive techniques is 1.5-2 times greater than the microhardness of a steel substrate. Liu et al. [10] 
described the shaped metal deposition (SMD) technique of applying bronze to low-carbon steel and was good bronze-steel adhesion, which was achieved, among other things, by the diffusion of silicon into iron with the formation of solid solutions. Freiße et al. [11] studied tribological characteristics of aluminum bronze coatings applied to steel by laser cladding. It was noted that the characteristics of the coating may depend on laser power. Wang et al. [12] compared characteristics of aluminum bronze coatings, applied to steel by plasma spraying in the first case and laser cladding in the second. It was noted that the microstructure of the laser deposited coating is more uniform and consists of finer microstructural components in comparison with plasma spraying. The loss on abrasion and friction coefficient depending on load in plasma coatings have a sudden change, so the stability of such a coating is worse than that of a laser cladded one.

Thus, the data available in the literature do not allow a generalized assessment of the characteristics of a bronze coating on steel depending on the laser power.

The purpose of this paper is a comprehensive study of the microstructural, strength, and tribological characteristics of aluminum bronze coatings deposited using additive technologies on structural steel, and further establishing the dependence of the coating properties on the power of the laser used.

\section{Materials and Methods}

As the coating material, we chose aluminum bronze powder (GTV GmbH, Luckenbach, Germany) (particles with sizes from 40 to 100 micrometers) of the following composition (weight \%): 8.5-10\% $\mathrm{Al}, 2-4 \% \mathrm{Fe}, 0.5 \% \mathrm{Mn}, 0.25 \% \mathrm{Si}, 0.6 \% \mathrm{Sn}$, and bal. Cu. According to [13], this bronze has good wear resistance indices. Low-alloyed structural steel used as a substrate had the composition (weight \%): $0.34 \%$ C, $0.38 \%$ Si, $0.68 \%$ Mn, $1.47 \%$ Cr, $1.53 \%$ Ni, $0.25 \%$ Mo, $0.017 \%$ S, $<0.035 \%$ P, and bal. Fe. The substrate material was used in the annealed state.

To apply the coating, a laser metal-cladding unit FL-Clad-R-4 was used (IPG IRE-Polus, IPG Photonics Corporation, Fryazino, Russia). The main unit of the complex can be represented as follows: (1) 4-kW laser head with an ytterbium fiber-optics laser with wavelength 1065-1075 nm (LS-4), the heating mode is continuous; (2) KUKA R-120 six-axis robot-equipped manipulator combined with KUKA DKP-400 double-axis positioning element; (3) TWIN-10-CR-2 powder feeder with a four-axis powder feed module; (4) process chamber-a metal cylinder with the diameter of $600 \mathrm{~mm}$ and the length of $1100 \mathrm{~mm}$. The trajectory of laser path was linear. Surfaced strips of coating partially overlapped each other. The overlap width was $1.8 \mathrm{~mm}$. The coating was carried out under shielding gas (argon), the flow rate of which was 20-22 L/min. Technological parameters of the process are given in Table 1.

The structure was studied on transverse sections of the samples, using the Axio Observer D1.m optical (Carl Zeiss Microscopy GmbH, Jena, Germany) inverted metallographic microscope equipped with the Thixomet Pro software (Thixomet Pro, Thixomet Company, Saint Petersburg, Russia) and hardware system for image analysis. The study of the transverse sections was also performed using the JEOL JSM-7001F scanning electron microscope (SEM) (JEOL, Tokyo, Japan) with Oxford Instruments energy dispersive x-ray spectrometer (EDS) (Oxford Instruments, Abingdon, UK) for quantitative and qualitative X-ray microanalysis (XRMA). The microstructure of the substrate was studied after etching in a $4 \%$ solution of nitric acid in ethanol.

Table 1. Manufacturing parameters of coating deposition.

\begin{tabular}{cccccc}
\hline No. & $\begin{array}{c}\text { Number of } \\
\text { Cycles }\end{array}$ & $\begin{array}{c}\text { Laser Power } \\
(\mathbf{W})\end{array}$ & $\begin{array}{c}\text { Laser Beam Travel } \\
\text { Speed }(\mathbf{m m} / \mathbf{s})\end{array}$ & $\begin{array}{c}\text { Spot Diameter } \\
(\mathbf{m m})\end{array}$ & $\begin{array}{c}\text { Powder Feed Rate } \\
(\mathrm{g} / \mathrm{min})\end{array}$ \\
\hline 1 & 2 & 600 & & & \\
2 & 2 & 1000 & 12 & 2 & 15 \\
3 & 2 & 1400 & & & \\
4 & 1 & 1800 & & & \\
5 & 1 & 2200 & & & \\
\hline
\end{tabular}


The microhardness of the coating and substrate (for steel in the initial (uncoated) annealed state) was measured on the FM-800 microhardness (Future-Tech Corp, Kawasaki, Japan) tester with a load of $25 \mathrm{~g}$. The number of microhardness measurements varied from 10 to 100 both across and along the obtained coating (the number of measurements depended on the thickness of the coating).

Tribological tests were carried out on the II-5018 friction machine (Tochpribor, Ivanovo, Russia) according to the scheme "movable roller-stationary roller (test material)". The material of the machine roller was $5140 \mathrm{H}$ steel, the radius of the both rollers was $45 \mathrm{~mm}$, the thickness was $10 \mathrm{~mm}$, the rotation speed was $300 \mathrm{rpm}$, the tests were carried out under dry friction conditions in at least three sections for each of the samples. Tribological tests were carried out at room temperature. Before testing, the friction surface was ground on an abrasive material with a grain size of $9 \mu \mathrm{m}$. The hardness of counter material was $490 \mathrm{HV}$. Wear loss was determined by measuring the thickness loss of the coating. The test time was determined by the length of the path traveled, which for the test samples was $100 \mathrm{~m}$. Wear rate was defined as the ratio of wear loss to the distance traveled.

\section{Results}

\subsection{Morphology and Microstructure}

The appearance of the resulting coating is shown in Figure 1. As the laser power increases (from Figure 1a to Figure 1e), the morphology of the coating surface changes: it covers a large area of the substrate material, becomes denser and smoother, and the roughness of the coating decreases.

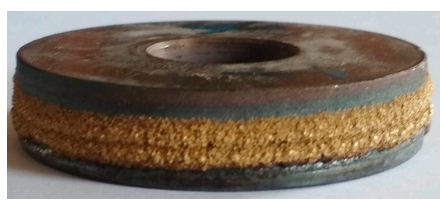

(a)

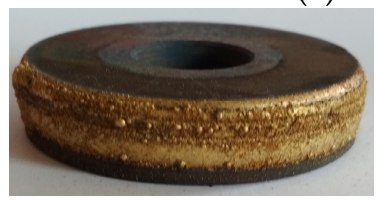

(c)

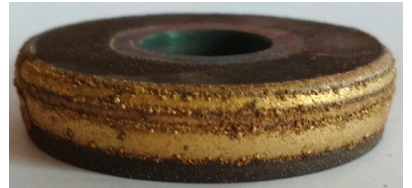

(d)

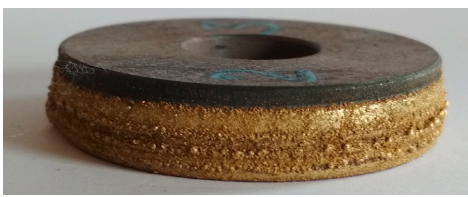

(b)

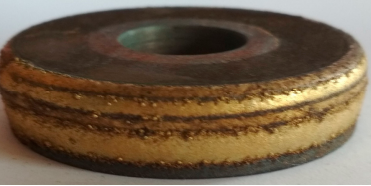

(e)

Figure 1. The appearance of the bronze coating obtained for samples: (a) No. 1; (b) No. 2; (c) No. 3; (d) No. 4; (e) No. 5. The outer diameter of all the rollers is $45 \mathrm{~mm}$.

When studying the transverse sections of experimental samples under the optical microscope, the thicknesses of the layer of deposited aluminum bronze were determined. For samples No. 1-3, due to the unevenness of the obtained coating, two cycles of laser surfacing were performed and the average thickness of the deposited bronze was $95 \mu \mathrm{m}$ for sample No. 1, $1115 \mu \mathrm{m}$ for sample No. 2 (the most uneven coating thickness with a minimum value of about $100 \mu \mathrm{m}$ ), and $1896 \mu \mathrm{m}$ for sample No. 3. For samples No. 4 and 5 (with a uniform layer of the bronze coating in one surfacing cycle), the average thicknesses of the coatings were 936 and $1047 \mu \mathrm{m}$, respectively. In Figure 2, profiles of the coatings of samples No. 2 and 5 are shown to be compared. 

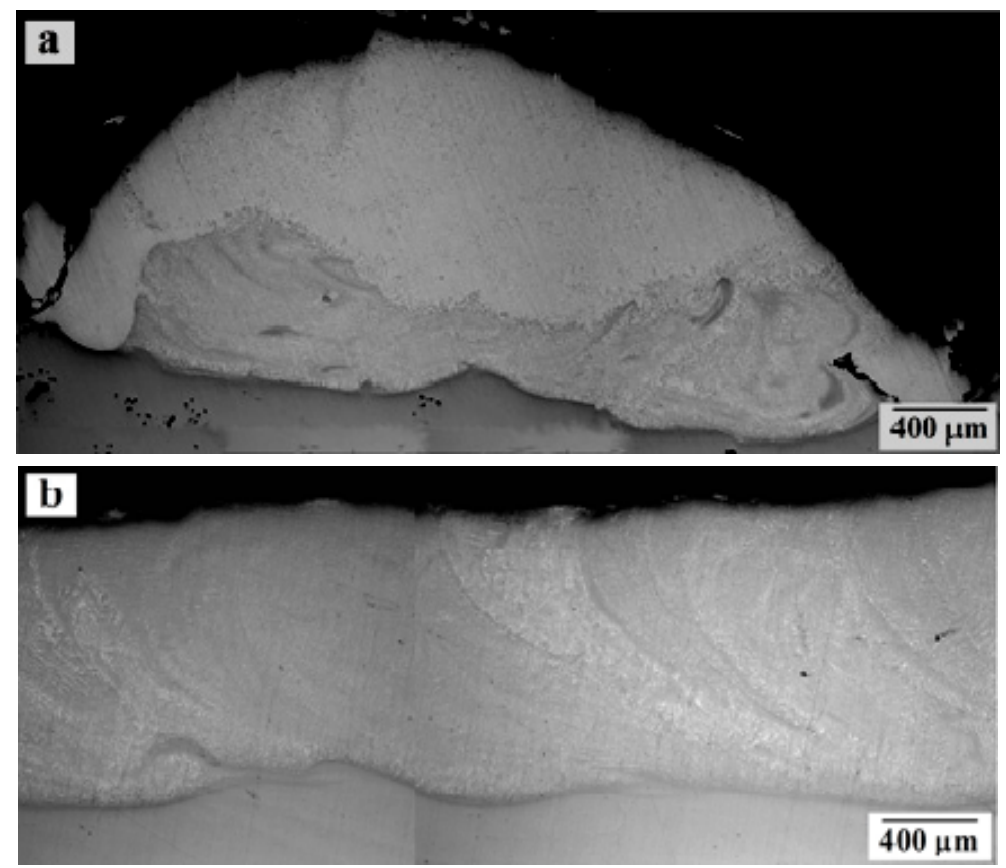

Figure 2. Coating profiles according to optical microscopy for samples: (a) No. 2 and (b) No. 5.

Using SEM, we studied the contact points of steel and the bronze coating on the transverse sections of the samples, as well as the microstructure of the resulting surfacing (Figures 3-5).

The transverse sections of samples after etching were studied using optical microscopy to determine the thermal effect on the microstructure of the substrate material-steel (Figure 6). The size of a heat-affected zone (HAZ) was estimated. For sample No. 1, the HAZ width was about $800 \mu \mathrm{m}$, for No. 2 it was $1167 \mu \mathrm{m}$, No. 3 had $1191 \mu \mathrm{m}$, No. 4 had $1473 \mu \mathrm{m}$, and No. 5 had $1892 \mu \mathrm{m}$.
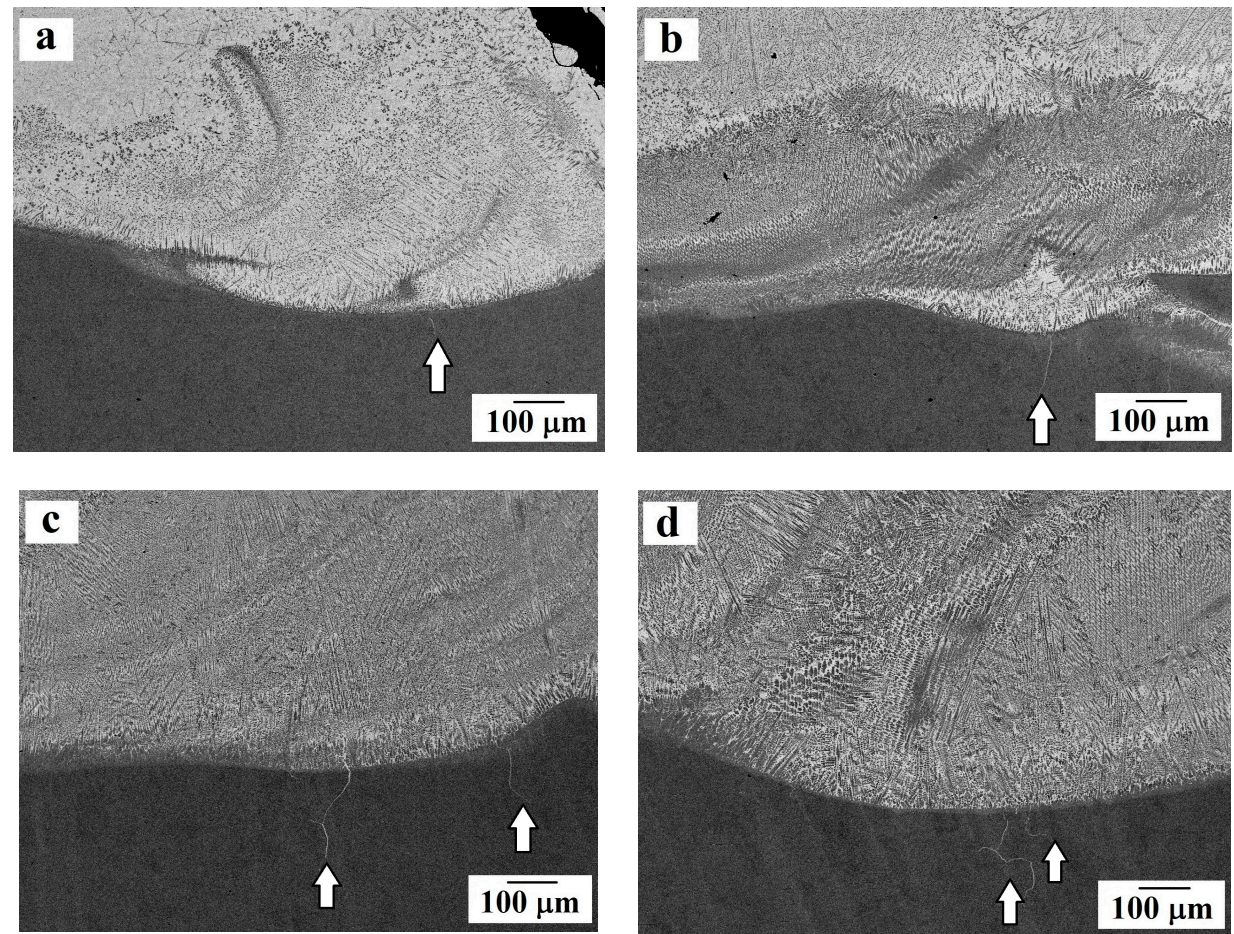

Figure 3. The microstructure of the substrate-coating contact zone (according to SEM data). General views for samples: (a) No. 2; (b) No. 3; (c) No. 4; (d) No. 5. Arrows indicate microcracks filled with bronze. 

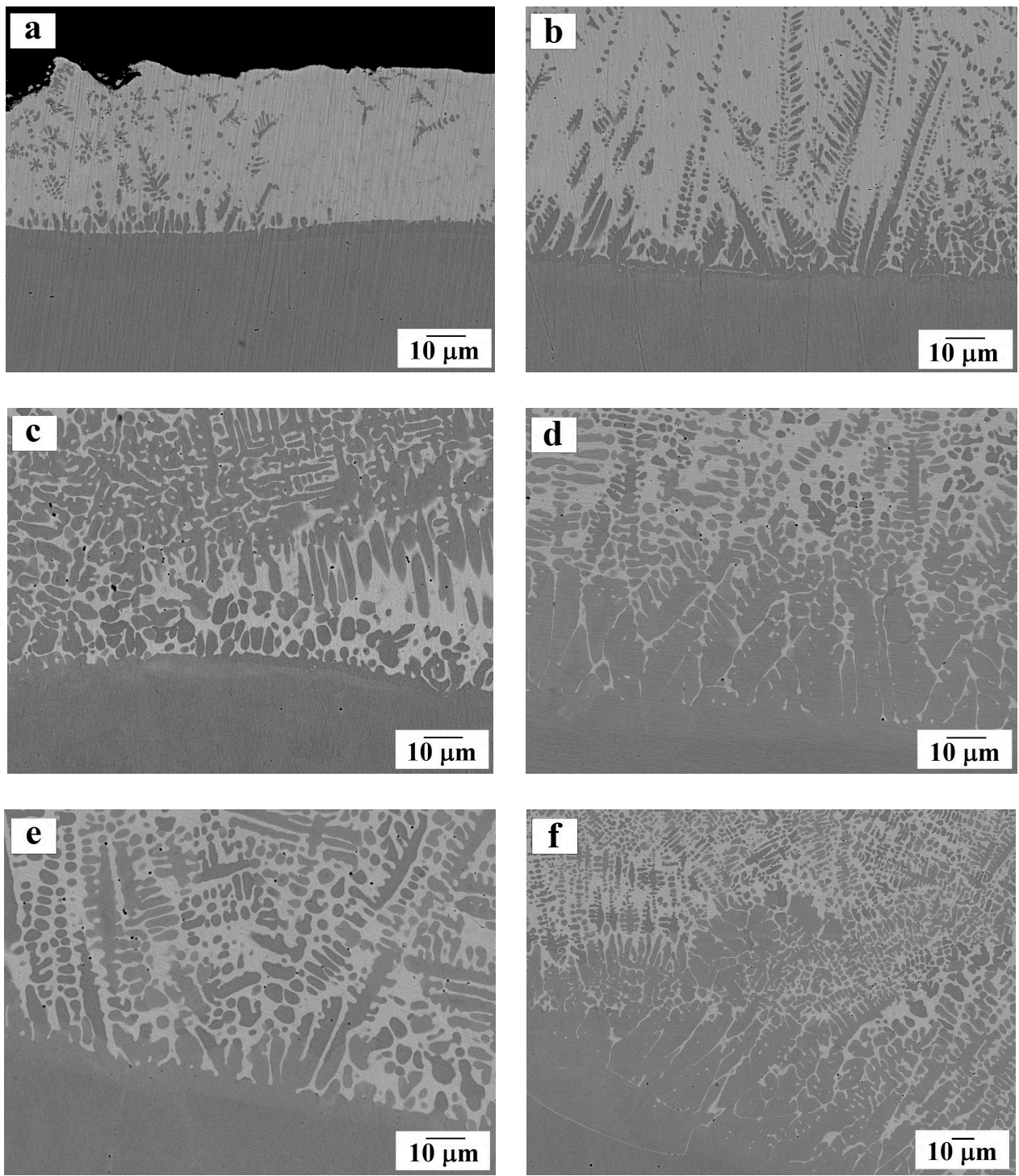

Figure 4. The microstructure of the substrate-coating contact zone (according to SEM data). Magnified fragments for samples: (a) No. 1; (b) No. 2; (c) No. 3; (d) No. 4; (e) and (f) No. 5. 

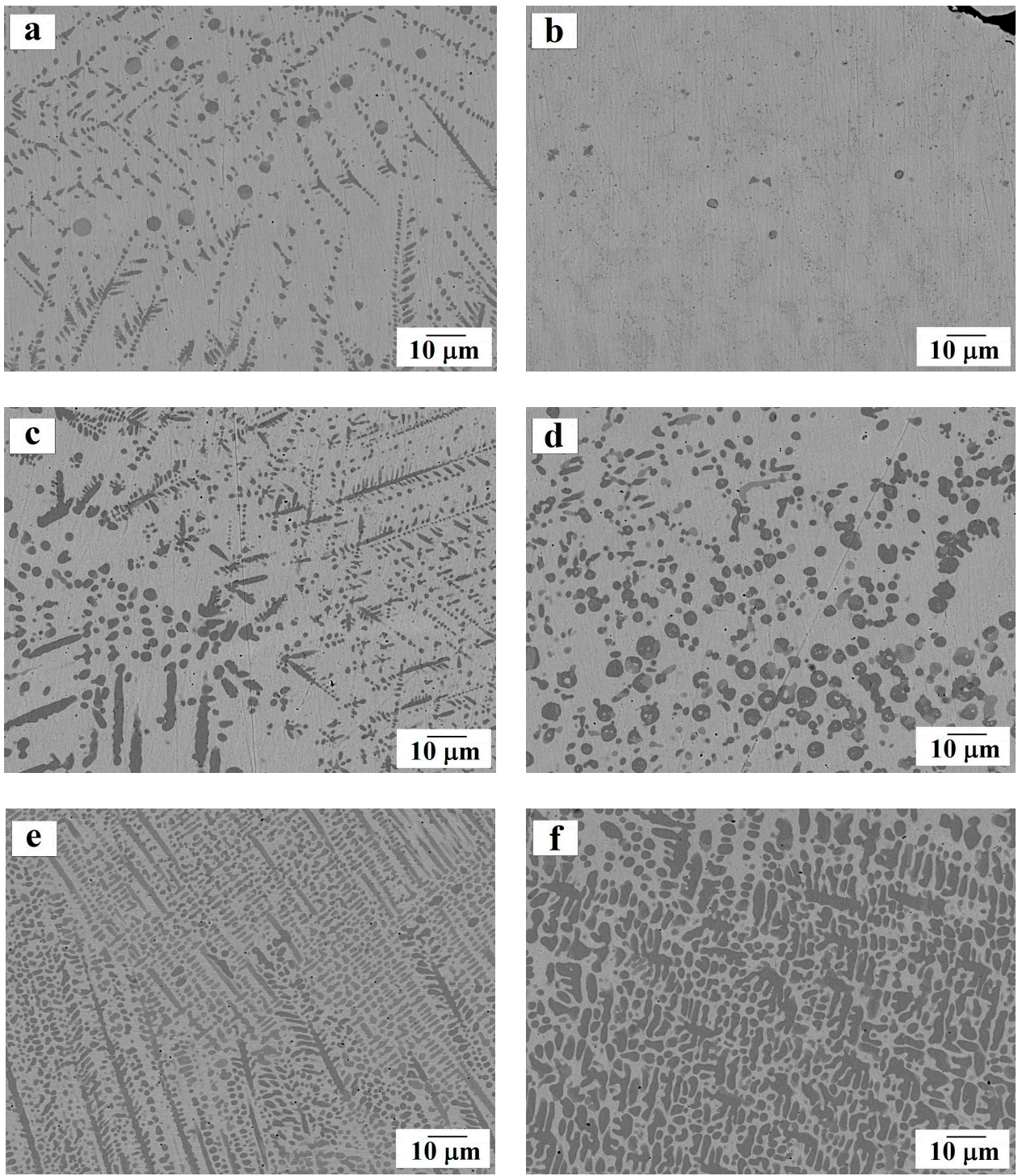

Figure 5. The microstructure of the central part of the obtained coating (according to SEM data) for samples: (a) and (b) No. 2; (c) and (d) No. 3; (e) No. 4; (f) No. 5.
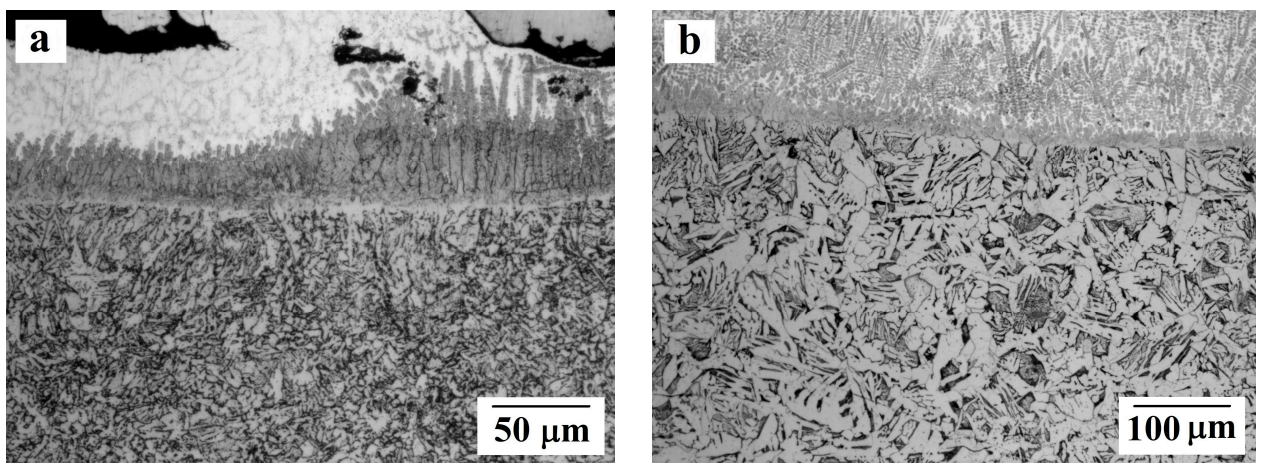

Figure 6. The HAZ microstructure (according to optical microscopy) for samples: (a) No. 1; (b) No. 5.

\subsection{XRMA Analysis}

Average compositions of the obtained composite coating, according to X-ray microanalysis data, are given in Table 2. With an increase in the laser power, the iron concentration in the coating volume 
increases, and the copper concentration falls. This is consistent with the observed microstructure, since with increasing laser power, the amount of iron dendrites in the coating microstructure increases.

Table 2. Average compositions of the obtained composite coating (according to XRMA), weight \%.

\begin{tabular}{cccccc}
\hline No. & Al & Si & Mn & Fe & Cu \\
\hline 1 & 7.49 & 0.07 & 0.11 & 12.87 & 79.46 \\
2 & 7.71 & 0.09 & 0.12 & 18.25 & 73.83 \\
3 & 7.96 & 0.09 & 0.06 & 24.25 & 67.64 \\
4 & 5.91 & 0.11 & 0.20 & 35.22 & 58.56 \\
5 & 4.98 & 0.14 & 0.31 & 44.95 & 49.62 \\
\hline
\end{tabular}

In the course of this study, in the transverse sections corresponding to the contact point of steel and the bronze coating, the X-ray microanalysis was performed, which confirmed the diffusion of copper and aluminum from bronze to steel (Figure 7). The study also found diffusion of aluminum and copper into iron dendrites permeating the microstructure of the coating itself.
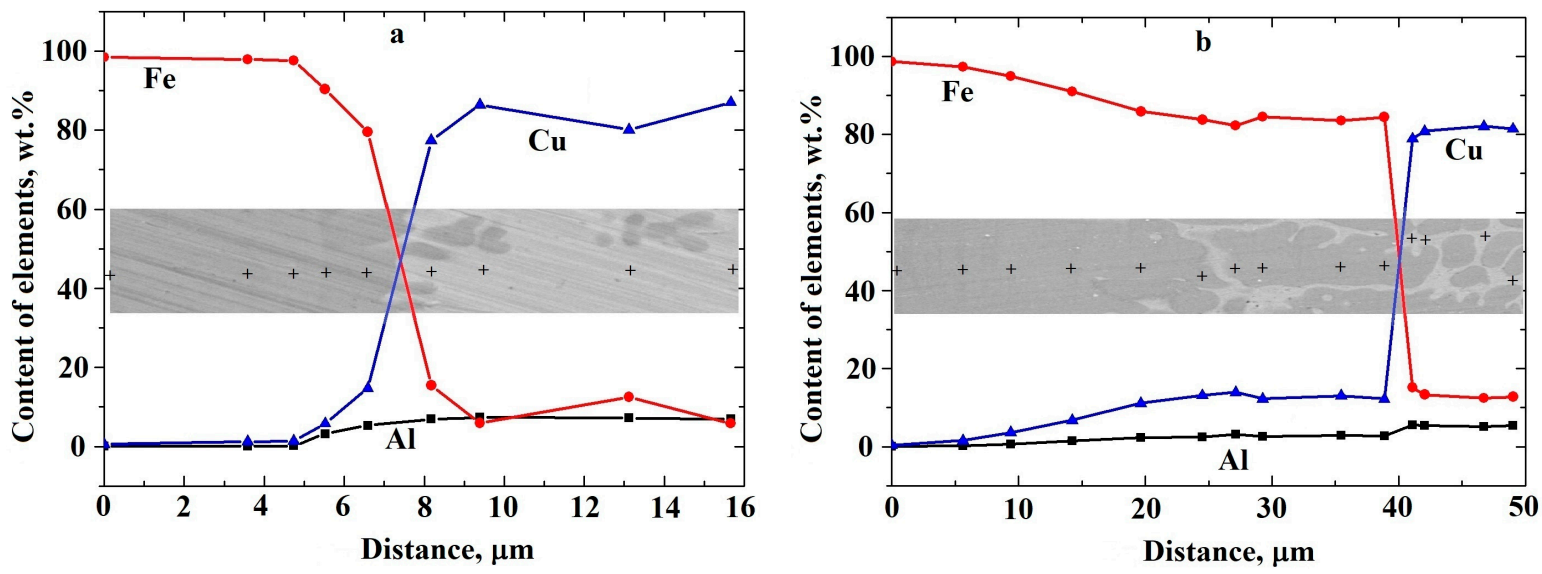

Figure 7. The results of the X-ray microanalysis for the contact zone of sample: (a) No. 1; (b) No. 5.

\subsection{Microhardness HV}

The microhardness of the deposited coating for test samples is characterized by a spread in the obtained $\mathrm{HV}$ values over the coating width, which is in good agreement with the observed microstructure.

Since sample No. 1 is characterized by low fusion of the substrate material with the coating material, the microhardness index was only $121 \mathrm{HV}$ in the upper part of the coating. When measuring the microhardness in the direction of the substrate, the HV index also increases and reaches a maximum of $270 \mathrm{HV}$ in the zone of iron dendrite formation (close to the contact zone, see Figure 4a).

For samples No. 2-5, the microstructure of the coating over the entire width corresponds to the structure of a composite material. However, as noted above, as the laser power increases, the microstructure becomes more uniform, which can also be traced by microhardness. So, for sample No. 2, the range of values is from 173 to $382 \mathrm{HV}$; No. 3 is from 191 to $368 \mathrm{HV}$; No. 4 is from 216 to $347 \mathrm{HV}$; No. 5 is from 232 to $328 \mathrm{HV}$.

\subsection{Tribological Investigations}

The results of tribological tests are given in Table 3. The friction coefficient is given for different loads of 200, 300, and $400 \mathrm{~N}$; wear rate is given for a sliding distance of $70 \mathrm{~m}$. For sample No. 1, such features of the applied coating as non-uniformity and discontinuity did not allow testing without significant error. So, the results for this sample in Table 3 are not shown. 
Table 3. The dry friction coefficient and wear rate (the average at the three different test loads) for the test sample coatings.

\begin{tabular}{ccccc}
\hline \multirow{2}{*}{ No. } & \multicolumn{3}{c}{ Dry Friction Coefficient * } & \multirow{2}{*}{ Wear Rate } \\
\cline { 2 - 4 } & $\mathbf{2 0 0} \mathbf{~ N}$ & $\mathbf{3 0 0 ~ N}$ & $\mathbf{4 0 0 ~ N}$ & \\
\hline 2 & 0.389 & 0.537 & 0.545 & $(6.96 \pm 0.74) \times 10^{-5}$ \\
3 & 0.422 & 0.563 & 0.563 & $(5.79 \pm 0.65) \times 10^{-5}$ \\
4 & 0.539 & 0.548 & 0.568 & $(4.62 \pm 0.48) \times 10^{-5}$ \\
5 & 0.541 & 0.548 & 0.574 & $(4.25 \pm 0.41) \times 10^{-5}$ \\
\hline \multicolumn{4}{c}{ * Measurement error did not exceed $5 \%}$.
\end{tabular}

\section{Discussion}

It can be seen that, using the low-power 1000-W laser (Figure 2a), we obtain a bumpy coating whose thickness (on the ridge and in the cavity) can vary by almost five times. When the laser power doubles (Figure 2b), the coating becomes more uniform in thickness (difference does not exceed 16\%). A similar trend in coating technology using additive technology was also noted by Schmidt et al. [9].

It was noticeable that during surfacing, fusion (mixing) of the substrate material (dark gray areas) with the coating material (light gray areas) occurred in the contact zone (see Figures 3 and 4). This led to the formation of a microstructure that is typical of a composite material in which a bronze coating plays the role of a matrix, and iron dendrites are a reinforcing component. Segments enriched with iron are found in both the contact zone and in the thickness of the coating. Such a microstructure is not observed for other methods of applying a bronze coating: in the works by Zhang et al. [7] and Alam et al. [8] obtained coating made of $\mathrm{Cu}-10 \mathrm{Al}-1 \mathrm{Fe}$ bronze was seen to exhibit a layered nature without precipitation of additional iron particles. However, such a "mixing" in the contact zone is observed by Liu et al. [10] when applying silicon bronze to steel by the shaped metal deposition method.

Precipitation of excess iron in our tested samples, both in the contact zone and in the thickness of the coating, can be explained as follows. When the coating is applied by laser heating, not only the sprayed aluminum bronze powder is melted, but also the top layer of the steel substrate, as a result of which a melt belonging to the $\mathrm{Cu}-\mathrm{Fe}$ system is formed in the contact zone. Note that the $\mathrm{Cu}-\mathrm{Fe}$ system is characterized by the absence of intermetallic compounds, unlimited solubility in the liquid state, and limited solubility in the solid state $[14,15]$. Thus, during the subsequent cooling of the molten bath, which proceeds from the substrate toward the outer surface, dendrites of more refractory iron begin to grow first, and only then the crystallization of the main coating occurs.

With an increase in laser power, the thickness of the melted substrate increases, and the coating is more intensively enriched with iron. The microstructure of the coating under increasing laser power becomes more uniform, but, at the same time, coarser: iron dendrites penetrating into bronze become larger while copper-based interdendritic matrix occupies a smaller area.

An interesting microstructure characterized by the appearance of the so-called "spherules" of iron is presented in Figure 5a,d. Such precipitates are typical of processes involving a supercooled liquid phase as well as for non-equilibrium crystallization in the $\mathrm{Cu}-\mathrm{Fe}$ system [16-20]. The precipitation of spherical iron particles in the tested samples is consistent with experimental data obtained by Freiße et al. [11] and Dai et al. [21] on the microstructure of an aluminum bronze coating obtained by laser cladding.

In samples No. 3-5, single cracks, starting in the contact zone, and going deep into the substrate metal no more than $300 \mu \mathrm{m}$, are observed. The cracks are not hollow, but filled with bronze, which should reduce the negative consequences of their formation.

According to the results of optical microscopy (see Figure 6), the heat-affected zone (HAZ) in steel has Widmanstätten microstructure that is typical for accelerated cooling of overheated steel. The observed microstructure of the HAZ is comparable with the microstructure of welded joints. The obtained data on the HAZ of experimental samples can be compared with the results by Freiße et al. [11], 
where in the zone bordering the deposited bronze coating, the microhardness of the steel shows a maximum and is about $600 \mathrm{HV}$, which indirectly indicates the formation of a heat-affected zone with nonequilibrium crystallization.

With increasing laser power, the HAZ width grows and the microstructure becomes coarser. Thus, the size of crystals in the HAZ comes close to $15 \mu \mathrm{m}$ for sample No. 1, and $100 \mu \mathrm{m}$ for sample No. 5, while the base metal (under the HAZ) is characterized by a ferrite-pearlite microstructure with grain sizes of about $10-15 \mu \mathrm{m}$.

Since the coating technology uses thermal effects, it can be assumed that a diffusion layer can appear at the interface between the steel substrate and the bronze coating with the formation of solid solutions that occur in the $\mathrm{Cu}-\mathrm{Al}-\mathrm{Fe}$ system [22-24].

The presence of a diffusion zone (see Figure 7) should facilitate the adhesion of the coating material to the substrate material, thereby providing good adhesion properties. The width of the diffusion zone in tested samples depends on the laser power and is about $5 \mu \mathrm{m}$ for sample No. 1 and $30 \mu \mathrm{m}$ for sample No. 5 (see Figure 7). Such values of the diffusion zone width are higher than that of a coating applied by electric arc method: according to Zhang et al. [7], copper diffusion from the bronze coating to steel was about $3 \mu \mathrm{m}$ while aluminum diffusion did not exceed $10 \mu \mathrm{m}$.

For all samples, the average microhardness of the coating is higher than that of the coating material itself (the HV of the aluminum bronze used is about 100) and higher than that of the substrate material (the HV of the structural steel used is 202), which is typical for composite materials.

According to Alam et al. [8], the microhardness of aluminum bronze coating applied to steel by plasma spraying varied from 100 to $160 \mathrm{HV}$ depending on the spraying conditions, which was on average one and a half times less than for our test samples. Furthermore, Freiße et al. [11] shown that the microhardness of the coating of the same grade of aluminum bronze deposited by laser on steel, averaged 200-220 HV.

The dry friction coefficient for the studied samples was 0.389-0.574, which is several times higher than for the samples coated with plasma spraying (according to Alam et al. [8], the friction coefficient at a load of $100 \mathrm{~N}$ ranged from 0.02 to 0.08 ). However, our data are comparable with those obtained by Freiße et al. [11], according to which the dry friction coefficient varied from 0.58 to 0.79 depending on the parameters of the applied surfacing for the laser-surfaced bronze $\mathrm{Cu}-10 \mathrm{Al}-1 \mathrm{Fe}$ coating on steel.

\section{Conclusions}

The results of the studies allow the following conclusions:

(1) The microstructure of the aluminum bronze coating applied to steel using additive techniques is typical of a composite material.

(2) An increase in laser power makes the coating profile dense, smooth, and more even in thickness, while the microstructure becomes more uniform, but at the same time, coarser.

(3) The thermal effect during coating promotes the diffusion of copper and aluminum from bronze to steel with the formation of a diffusion zone 5-30 $\mu \mathrm{m}$ wide, which should facilitate adhesion of the coating material to the substrate material.

(4) When surfacing, overheating occurs in the heat-affected zone in the substrate, which leads to the formation of a layer with the Widmanstätten microstructure. The depth of such an overheated layer depends on the laser power.

(5) The microhardness of the applied coating is 1.5-2.5 times higher than the microhardness of aluminum bronze or the used steel grade in its pure form.

(6) The absolute values of hardness over the thickness of the coating are consistent with its microstructure, that is, fluctuations are observed.

(7) According to the results of tribological tests, this coating cannot be considered as antifriction, but rather as a promising material for coating, for example, brake pads. 
Author Contributions: Conceptualization, M.S., N.S., K.P., V.M.; Methodology, N.S., I.E.; Validation, O.S. and L.R.; Investigation, N.S. and O.S.; Writing-Review and Editing, O.S. and N.S.; Project Administration, M.S., R.Z., L.R. and E.T. All authors have read and agreed to the published version of the manuscript.

Funding: This research study was carried out as part of Government of the Russian Federation (Act 211, contract № 02.A03.21.0011) and by the Ministry of Education and Science of the Russian Federation (4.5749.2017/7.8); and was support from the Ministry of Education and Science of the Russian Federation in the framework of the project "Development of new methods and technologies to create products for electrical and structural application of graphitic composite materials by means of high-speed dynamic molding" of the State task № 9.1329.2017/4.6.

Conflicts of Interest: The authors declare no conflict of interest.

\section{References}

1. Prasad, B. Sliding wear behaviour of bronzes under varying material composition, microstructure and test conditions. Wear 2004, 257, 110-123. [CrossRef]

2. Ghorbani, M.; Mazaheri, M.; Afshar, A. Wear and friction characteristics of electrodeposited graphite-bronze composite coatings. Surf. Coatings Technol. 2005, 190, 32-38. [CrossRef]

3. Kimura, T.; Shimizu, K.; Terada, K. Sliding wear characteristic evaluation of copper alloy for bearing. Wear 2007, 263, 586-591. [CrossRef]

4. Ünlü, B.S. Investigation of tribological and mechanical properties of metal bearings. Bull. Mater. Sci. 2009, 32, 451-457. [CrossRef]

5. Gao, F.; Liu, R.; Wu, X. Tribological behavior of T-401/tin-bronze composite coating deposited by HVOF on the bushing of planet journals. Wear 2010, 269, 724-732. [CrossRef]

6. Equey, S.; Houriet, A.; Mischler, S. Wear and frictional mechanisms of copper-based bearing alloys. Wear 2011, 273, 9-16. [CrossRef]

7. Zhang, Z.-L.; Li, D.-Y.; Wang, S.-Y. High temperature performance of arc-sprayed aluminum bronze coatings for steel. Trans. Nonferrous Met. Soc. China 2006, 16, 868-872. [CrossRef]

8. Alam, S.; Sasaki, S.; Shimura, H. Friction and wear characteristics of aluminum bronze coatings on steel substrates sprayed by a low pressure plasma technique. Wear 2001, 248, 75-81. [CrossRef]

9. Schmidt, M.; Kolleck, R.; Grimm, A.; Veit, R.; Bartkowiak, K. Direct laser deposition of Cu alloy on forming tool surfaces-Process window and mechanical properties. CIRP Ann. 2010, 59, 211-214. [CrossRef]

10. Liu, L.; Zhuang, Z.; Liu, F.; Zhu, M. Additive manufacturing of steel-bronze bimetal by shaped metal deposition: interface characteristics and tensile properties. Int. J. Adv. Manuf. Technol. 2013, 69, 2131-2137. [CrossRef]

11. Freiße, H.; Langebeck, A.; Köhler, H.; Seefeld, T.; Vollertsen, F. Investigations on dry sliding of laser cladded aluminum bronze. Manuf. Rev. 2016, 3, 13. [CrossRef]

12. Wang, H.; Wang, Z.; Lu, Y.; Li, Y.; Tian, G. Study on friction and wear properties of plasma and laser coatings of aluminium bronze powder. Adv. Mater. Res. 2011, 148-149, 621-627. [CrossRef]

13. Yasar, M.; Demiral, M.; Özyürek, D.; Unal, M. Investigation of wear behaviors of C95200-C95300 Cu-Al-Fe alloys. Ind. Lubr. Tribol. 2009, 61, 40-46. [CrossRef]

14. Hasebe, M.; Nishizawa, T. Calculation of phase diagrams of the iron-copper and cobalt-copper systems. Calphad 1980, 4, 83-100. [CrossRef]

15. Chen, Q.; Jin, Z. The Fe-Cu system: A thermodynamic evaluation. Met. Mater. Trans. A 1995, 26, 417-426. [CrossRef]

16. Wang, C.P.; Liu, X.J.; Kainuma, R.; Takaku, Y.; Ohnuma, I.; Ishida, K. Formation of core-type macroscopic morphologies in Cu-Fe base alloys with liquid miscibility gap. Met. Mater. Trans. A 2004, 35, 1243-1253. [CrossRef]

17. He, J.; Zhao, J. Behavior of Fe-rich phase during rapid solidification of Cu-Fe hypoperitectic alloy. Mater. Sci. Eng. A 2005, 404, 85-90. [CrossRef]

18. He, J.; Zhao, J.Z.; Ratke, L. Solidification microstructure and dynamics of metastable phase transformation in undercooled liquid Cu-Fe alloys. Acta. Mater. 2006, 54, 1749-1757. [CrossRef]

19. Liu, S.; Jie, J.; Dong, B.; Guo, Z.; Wang, T.; Li, T. Novel insight into evolution mechanism of second liquid-liquid phase separation in metastable immiscible Cu-Fe alloy. Mater. Des. 2018, 156, 71-81. [CrossRef] 
20. Liu, S.; Jie, J.; Guo, Z.; Yin, G.; Wang, T.; Li, T. Solidification microstructure evolution and its corresponding mechanism of metastable immiscible Cu80Fe20 alloy with different cooling conditions. J. Alloys Compd. 2018, 742, 99-106. [CrossRef]

21. Dai, X.; Xie, M.; Zhou, S.; Wang, C.; Gu, M.; Yang, J.; Li, Z. Formation mechanism and improved properties of $\mathrm{Cu} 95 \mathrm{Fe} 5$ homogeneous immiscible composite coating by the combination of mechanical alloying and laser cladding. J. Alloys Compd. 2018, 740, 194-202. [CrossRef]

22. Ohtani, H.; Suda, H.; Ishida, K. Solid/liquid equilibria in Fe-Cu based ternary systems. ISIJ Intern. 1997, 37, 207-216. [CrossRef]

23. Miettinen, J. Thermodynamic description of the $\mathrm{Cu}-\mathrm{Al}-\mathrm{Fe}$ system at the $\mathrm{Cu}-\mathrm{Fe}$ side. Calphad 2003, 27, 91-102. [CrossRef]

24. Raghavan, V. Al-Cu-Fe (aluminum-copper-iron). J. Phase Equilib. Diff. 2005, 26, 59-64. [CrossRef]

(C) 2020 by the authors. Licensee MDPI, Basel, Switzerland. This article is an open access article distributed under the terms and conditions of the Creative Commons Attribution (CC BY) license (http://creativecommons.org/licenses/by/4.0/). 